\title{
EN TORNO AL NOMBRE ADJETIVO EN EL DISCURSO ORAL DE LOS NIÑOS ESCOLARES COSTARRICENSES: LINEAMIENTOS PARA SU ENSEÑANZA
}

\author{
Máster Marielos Murillo Rojas ${ }^{1}$
}

Resumen: Diversos ámbitos e instituciones suelen manifestar que los niños y jóvenes costarricenses carecen de destrezas suficientes para expresar y comprender textos. Por ello, se han generado una serie de estudios relacionadas con la competencia lingüística del educando costarricense, entre ellos el LEBAESCO (base de este estudio), que pretende registrar el léxico básico de los escolares ticos.

El artículo se aboca en particular a la amplitud de adjetivos que los escolares emplean, y registra algunos aspectos teóricos que sustentan la conceptualización y clasificación de dicha categoría. Asimismo, se recoge una muestra que comprende textos orales emitidos por niños entre los 7 y 14 años de edad, tanto de escuelas públicas como privadas. Posteriormente, se categorizaron y analizaron los adjetivos empleados y registrados en LEBAESCO.

Según los datos arrojados por el artículo, se concluye que es importante que el sistema educativo costarricense dedique mayor espacio y énfasis a la enseñanza de la lengua materna, no solo en el estudio de la dimensión de categoría gramatical del adjetivo, en este caso, sino como instrumento para el enriquecimiento léxico. De igual manera, se debe tener en cuenta que el LEBAESCO puede facilitar la planificación de la enseñanza para el diseño de estrategias de incorporación al sistema educativo.

Palabras clave: EDUCACIÓN PRIMARIA/ DESTREZAS/ COMPRENSIÓN DE TEXTO/ LENGUA MATERNA/ SISTEMA EDUCATIVO COSTARRICENSE/ LÉXICO/

\section{Introducción}

Es frecuente escuchar en los ámbitos gubernamental, universitario y escolar de Costa Rica que los niños y jóvenes carecen de destrezas suficientes para expresar y comprender textos en su lengua materna.

En consecuencia se han generado investigaciones fundamentadas sobre la base de marcos teóricos etnográficos, psicológicos y lingüísticos, con el fin de atender desde diferentes ángulos esta problemática.

Dado lo anterior, la lingüística aplicada a la enseñanza de la lengua materna se ha abocado al estudio de la competencia lingüística del educando, con el propósito de aportar nuevos conocimientos que a mediano o largo plazo contribuyan a revertir esta situación.

\footnotetext{
1 Máster en Lingüística. Licenciada en Educación

Preescolar. Profesora de la Escuela de Formación

Docente, Universidad de Costa Rica. Áreas de interés el español como lengua materna en preescolares $y$ lectoescritura.

e-mail: mamurillo2001cr@yahoo.com
} 
La elaboración de programas de estudio y de los materiales didácticos, la planificación de los procesos de aprendizaje y la organización de actividades de adquisición de la lengua materna, deben fundamentarse en un conocimiento de la competencia lingüístico-comunicativa de los educandos, en los distintos componentes de la lengua: fonológico, morfosintáctico, léxico-semántico y en la competencia discursiva (Sánchez, 1995, p. 75).

En este momento el conocimiento que se tiene en Costa Rica sobre la competencia lingüística-comunicativa de los niños y jóvenes que forman parte del sistema educativo se encuentra en una etapa inicial.

Apenas se cuenta con tres estudios con validez nacional, a saber: "Léxico básico preescolar costarricense", "Léxico disponible del preescolar costarricense", y "Léxico básico escolar costarricense: código oral", -identificado con el acrónimo LEBAESCO-, todos proyectos inscritos en la Vicerrectoría de Investigación por Marielos Murillo y Víctor Sánchez; los dos primeros concluidos y el tercero en su etapa final. Además, se cuenta con una serie de artículos, que aportan información importante para este campo de estudio.

Como puede observarse, se ha enfatizado en la identificación del léxico tanto básico como disponible, pero están pendientes los análisis cualitativos de las diferentes categorías gramaticales, con miras hacia la presentación de lineamientos para la enseñanza del léxico.

Expuesto lo anterior y consciente de la necesidad de contribuir en la enseñanza del léxico en el sistema educativo costarricense, se analizarán en este artículo los 529 adjetivos presentes en el LEBAESCO, a partir de las tres clases léxico-sintácticas de adjetivos que expone ampliamente Violeta Demonte en el artículo "El adjetivo: clases y usos. La posición del adjetivo en el sintagma nominal" (Madrid, 1999) , a saber:

1) adjetivos relacionales

2) adjetivos calificativos

3) adjetivos adverbiales intensionales y circunstanciales

Los dos primeros se refieren a la asignación de propiedades a los nombres. El tercero, indica únicamente la manera como el concepto o intensión de un término se aplica a un determinado referente. 
Como bien se sabe, los adjetivos son palabras que se aplican a otras palabras que nombran objetos físicos o mentales. Más específicamente un adjetivo modificador adscribe propiedades cuya especificación sirve para definir o delinear con mayor precisión a la entidad mentada, para caracterizarla e identificarla entre varias similares, para clasificarla o establecer taxonomías culturales y científicas.

En vista de lo anterior, conocer las características de los adjetivos que usan los niños les permitirá al planificador curricular y al maestro tomar decisiones más certeras respecto de la orientación de su enseñanza.

\section{Aspectos teóricos}

\subsection{El adjetivo}

Violeta Demonte (1999, p. 133), define el adjetivo en los siguientes términos:

es una categoría gramatical: una clase de palabras cuyos miembros tienen unas características muy precisas; y es también una categoría semántica: hay un tipo de significado que se expresa preferentemente por medio de adjetivos. Como categoría gramatical puede ser un atributo o modificador del nombre sustantivo; unido a él, y a sus determinantes y cuantificadores, forma una frase nominal en la cual ha de concordar en género y número con el nombre modificado.

Asimismo, esta autora define al adjetivo a través de los siguientes rasgos: generalidad o independencia del objeto, capacidad para adscribir propiedades o características a los objetos y a los acontecimientos y gradualidad.

Por otra parte, clasifica los adjetivos en tres clases léxico-sintácticas, a saber: adjetivos relacionales, adjetivos calificativos y adjetivos adverbiales intensionales y circunstanciales. No considera a los determinantes (los artículos, posesivos y demostrativos) y a los cuantificadores (los numerales e indefinidos), pues constituyen clases cerradas con un número fijo de miembros desprovistos de significado léxico.

La conceptualización del adjetivo que presenta Alarcos Llorach (1994/2000) se enmarca dentro de la gramática tradicional, pues lo define como un tipo de palabra que acompaña al 
sustantivo y forma con este un grupo unitario que cumple en el enunciado la misma función que podría desempeñar aislado. Desde ese marco teórico clasifica los adjetivos en: calificativos y determinativos. Estos últimos los subdivide en: demostrativos, posesivos, numerales, indefinidos y relativos.

Por otro lado, Gómez Torrego (1997/2000) al referirse a la definición del adjetivo señala que tradicionalmente se ha definido como una palabra que expresa cualidad, pero este tipo de definición no es exacta, pues solo atiende al significado y algunos adjetivos también significan estados, relaciones, etc. Respecto de la clasificación los divide en: calificativos (bueno, malo), de relación o pertenencia (musical, ocular), gentilicios (madrileño, ruso) y cuasideterminativos (siguiente, último).

Como puede observarse, las conceptualizaciones del nombre adjetivo y su clasificación dependen en gran medida del marco teórico con el que trabaje el gramático. Esto no significa que unas sean mejores que otras, sino simplemente que responden a diferentes concepciones teórico-metodológicas.

En vista de lo anterior y por razones didácticas, en este trabajo se utilizará la concepción de adjetivo y su respectiva clasificación de Violeta Demonte.

\subsection{Clasificación de los adjetivos}

\subsubsection{Los adjetivos relacionales}

Los adjetivos relacionales asignan un conjunto de propiedades al nombre, con las que este establece una relación semántica determinada.

Demonte (1999) presenta de forma exhaustiva y ejemplificada nueve contextos o situaciones sintácticas que permiten distinguir estos adjetivos respecto de los calificativos, por lo que en pro de una comprensión más amplia se remite a la lectura de ese estudio.

Las características morfológicas de estos adjetivos son precisas y específicas.

En primera instancia, estos adjetivos son siempre sufijales y derivan de nombres. Los sufijos derivacionales son muy numerosos, sirvan como ejemplo: al/ar, ario, ano, ico, ivo, ista, esco, 
il, pues en español se documentan alrededor de setenta sufijos aptos para la derivación de adjetivos de relación. Téngase en cuenta que estos sufijos no son exclusivos de este tipo de adjetivos, ya que pueden aparecer también en los adjetivos calificativos.

También es característico de estos adjetivos ir acompañados por prefijos preposicionales como ante, prefijos adverbiales del tipo pre o anti y prefijoides del estilo neo o paleo.

Por otra parte, Demonte (1999, passim) establece tres clases de adjetivos relacionales, según el valor semántico en la relación de modificación:

a) El adjetivo tiene el valor semántico que correspondería a una función gramatical canónica (producción artesanal / producción de artesanía); estos valores solo se dan cuando el nombre modificado es una nominalización, o sea se derivan de verbos.

b) El adjetivo adopta una entre una serie de valores semánticos adjuntos (locativo, instrumental, causal, final, posesivo, etc.).

c) El adjetivo tiene un significado integrable en el nombre, este significado corresponde a la relación parte-todo, continente-contenido, forma-fondo u otras similares, que se asocia a la preposición "de" en construcciones como mesa de madera, idea de los jóvenes, actitud de los varones, etc.

Esos grupos de adjetivos relacionales se subdividen a su vez en varias subclases, tantas como permita la valencia del verbo del que proviene el nombre deverbal, de un lado, y tantas como papeles semánticos adjuntos pueden asociarse a los nombres comunes.

Por otra parte, el hecho de que este tipo de adjetivos se vea envuelto en una gama tan variada de relaciones semánticas implícitas y de significados posibles determina que los adjetivos sean múltiples, ambiguos y que formas aparentemente paralelas resulten inconstantes en los significados que admiten.

Como puede observarse, el significado de los adjetivos relacionales depende en gran medida del significado del nombre al que modifican, por lo que resulta difícil analizar estos 
adjetivos en ausencia del nombre modificado y, aún más, del enunciado del que forman parte.

\subsubsection{Los adjetivos calificativos}

Los adjetivos calificativos, a diferencia de los relacionales, asignan una propiedad que puede ser estable (individual) o transitoria (episódica).

Desde el punto de vista morfológico, una gran mayoría de estos adjetivos son formas primitivas, aunque hay bastantes calificativos derivados de formas verbales como los acabados en los sufijos dor/tor, ante, oso, udo, ble. Por otra parte, los calificativos no derivativos atribuyen cualidades esenciales o características: indican los rasgos que distinguen a un objeto de otro (niña alta frente a niña baja), la situación de una entidad con respecto a la norma (hombre feo/mesa nueva), las propiedades que permiten identificarlos (pared blanca/persona jovial).

Las principales características de los adjetivos calificativos son la gradualidad y polaridad.

La existencia de un constituyente de grado se manifiesta de varias maneras en la sintaxis de los adjetivos: en primer lugar, la posibilidad de llevar adverbios de intensificación; en segundo lugar, el hecho de que pueden constituir construcciones comparativas y construcciones de medida de diversa forma (extremadamente gordo, demasiado grande).

Igualmente, algunos participan en oposiciones de polaridad, o sea, forman pares de adjetivos que representan los grados extremos de una cualidad o característica (bueno-malo, clarooscuro).

Demonte (1999, passim) clasifica los adjetivos calificativos a partir de las clases establecidas por Dixon (1977) y las complementa con consideraciones propias. De esta forma los adjetivos calificativos se clasifican en:

a) Adjetivos de dimensión.

b) Adjetivos de velocidad.

c) Adjetivos de propiedad física.

d) Adjetivos de color.

e) Adjetivos de edad. 
f) Adjetivos de valoración o evaluativos.

g) Adjetivos de aptitudes y (pre)disposiciones humanas.

\subsubsection{Los adjetivos adverbiales}

Los adjetivos adverbiales son todas las formas adjetivas paralelas a los adjetivos calificativos, pero que no constituyen expresiones asignadoras de propiedades.

Se agrupan en dos grandes clases: adjetivos adverbiales intensionales y adjetivos adverbiales circunstanciales. Los primeros modifican las propiedades de un referente, o sea la intensión y no al objeto designado por el sustantivo. Los otros se refieren a los objetos o procesos en cuanto entidades que tienen lugar, que acontecen de cierta manera en el tiempo y en el espacio.

\section{Aspectos metodológicos}

En este trabajo se tomó como base "El léxico básico escolar costarricense: código oral" (Murillo y Sánchez, en prensa), estudio sobre la producción textual discursiva de 210 escolares, cuya edad estaba comprendida entre los 7 y los 14 años, pertenecientes a treinta y cinco escuelas públicas y privadas, ubicadas en las veinte regiones educativas del país, corresponde a una muestra estadísticamente representativa de la educación primaria costarricense.

El corpus de esa investigación comprende textos orales emitidos por los niños de la muestra y está constituido aproximadamente por 140 horas de grabación, en total 333. 692 palabras de discurso, de contenido léxico.

Para la conformación de la muestra se tomaron en cuenta las variables: sexo (niños y niñas), tipo de escuela (privada, urbana, rural) y nivel educativo. De esta forma se logró aportación de la misma cantidad de niños y niñas, de los diferentes tipos de escuelas que conforman la educación primaria costarricense, en proporción al tamaño, y los niveles educativos de los niños, en cada escuela se trabajó con el primer nivel, tercero y sexto, con el objetivo de que estuviera incluido todo el rango que comprende la educación primaria en Costa Rica. 
Por otra parte, se dio la posibilidad al niño de estructurar textos orales en universos temáticos amplios y cercanos a su realidad, a saber: el niño y su entorno, la escuela, materias básicas, el niño y la vida social y el niño y su yo interno.

Detengámonos en cada una de las variables tomadas en cuenta; la primera, el sexo, las niñas aportaron un total de $51,4 \%$ y los niños un $48,6 \%$ del total del corpus, datos aunque muy cercanos porcentualmente, pero reafirman lo encontrado por un sinnúmero de investigaciones psicolingüísticas y de lingüística aplicada, en las que se señala que las niñas tienen más ventajas lingüísticas que los niños. Igualmente, en el corpus del "Léxico básico preescolar costarricense", 2002, se encontró una situación similar, pues en esa investigación los niñas aportaron un $51,3 \%$ del texto oral y los niños un $48,7 \%$.

Respecto de la variable "tipo de escuela", el corpus está formado mayoritariamente por aportaciones de los niños de la escuela urbana costarricense, con un $47,9 \%$, seguido de la escuela rural, con un 44,1 y, por último la escuela privada con un aporte del $8 \%$.

Por su parte, la variable nivel escolar nos muestra que en la medida que avanza el niño en escolaridad crece su universo conceptual y, como resultado, aporta mayor cantidad de texto, pues los escolares de primer grado produjeron el $26,5 \%$, los de tercer grado 31,8 y los de sexto grado 41,8 del corpus.

Los universos léxicos "la escuela", "materias básicas", "el niño y la vida social", "el niño y su entorno" y "el niño y su yo interno", tenían como objetivo motivar al niño para que generara discurso oral; no obstante, también dan información sobre la realidad del niño en edad escolar, pues los textos con mayor porcentaje son "la escuela" $(25,2 \%)$ y "las materias básicas" $(21,1 \%)$, ambos propios del mismo ambiente, hecho que acrecienta la responsabilidad de la escuela en la creación de situaciones de aprendizaje con temas variados y acordes con los intereses escolares y extraescolares de los educandos y su aprovechamiento en la enseñanza de la expresión oral y la competencia comunicativa en general.

Por otra parte, este corpus está constituido por aproximadamente 140 horas de grabación del texto emitido por los niños, ya que se obviaron las preguntas y enunciados motivacionales expresados por el entrevistador. 
EI LEBAESCO, "Léxico básico escolar costarricense: código oral", comprende una nomenclatura de 5277 lemas o tipos.

La presentación del léxico se hizo siguiendo los patrones que ofrece el Léxico básico del niño preescolar costarricense (Murillo y Sánchez, 2002). Conviene recordar que, de acuerdo con ese procedimiento, los adjetivos procedentes de participios se colocaron dentro del verbo correspondiente. Cada forma aparece integrada bajo un lema en orden alfabético y se ofrece en ella la frecuencia total más los índices de uso y de dispersión.

EI LEBAESCO está constituido por: 3069 sustantivos, 529 adjetivos, 1096 verbos, 126 adverbios, 281 nombre-adjetivos, 110 nombres pluriverbales, 25 frases adverbiales, 13 nombres marca, 15 frases prepositivas, 15 conectores, para un total de 5277 entradas léxicas.

En consecuencia, el presente estudio tomó únicamente los 529 adjetivos y analizó siguiendo la clasificación supracitada, Violenta Demonte (1999), de tal forma que se organizaron en:

- adjetivos descriptivos

- adjetivos relacionales

- adjetivos adverbiales intensionales y circunstanciales

Por otra parte, a la educación general básica costarricense, se ofrecieron recomendaciones didácticas en función del enriquecimiento de esta categoría gramatical.

\section{Análisis de los adjetivos presentes en el LEBAESCO}

\subsection{Adjetivos calificativos}

Se partió de la categorización en clases léxico semánticas: adjetivos de dimensión, velocidad, propiedad física, color (y forma), edad, temperatura, sabor, olor, sonoridad, valoración, aptitudes y (pre)disposiciones humanas.

\subsubsection{Adjetivos de dimensión o tamaño}

Este término designa los tres tipos de dimensiones espaciales de los objetos físicos (largo/alto, ancho y volumen o profundidad). Estos adjetivos aparecen en pares de 
antónimos polares y la forma positiva de esa oposición representa por lo general la oposición en sí.

Las formas largo, corto, grande y pequeño pueden emplearse también como adjetivos adverbiales e indicar la dimensión temporal y duración de un acontecimiento.

Dentro del léxico básico de los escolares se encuentran los siguientes grupos de adjetivos dimensionales, a saber:

- ancho-amplio-extenso-angosto,

- alto-bajo,

- grande-enorme-mediano- pequeño-chiquito-minúsculo,

- grueso-delgado-flaco-fino,

- largo-corto-chingo,

- superior-inferior,

- hondo.

Como puede apreciarse la noción de profundidad está prácticamente ausente, pues el único adjetivo que se refiere a esta es hondo.

Por otra parte, si se toma como punto de partida esta pequeña lista de adjetivos dimensionales, se pueden plantear actividades educativas que conduzcan a su crecimiento, en pro de una mayor precisión al describir los objetivos físicos.

\subsubsection{Adjetivos de velocidad}

Los adjetivos de velocidad son relativos y polares al igual que los de dimensión física, pues la forma positiva posee el valor no marcado de la oposición.

Los adjetivos básicos de este grupo son: rápido, lento, lerdo, veloz y, a partir de estos tendríamos una amplia gama de formas derivadas.

En el LEBAESCO únicamente aparecen rápido-lento, adjetivos que servirán como referencia para enriquecer este grupo. En consecuencia, el educador tendrá como responsabilidad crear situaciones de aprendizaje en las cuales, se enriquezca la competencia lingüística con 
otros adjetivos como "veloz", insertados en contextos que posibiliten su uso y, por lo tanto, que se incorporen en el vocabulario de expresión.

\subsubsection{Adjetivos de propiedad física}

Este campo referencial agrupa los adjetivos que nombran las propiedades de los objetos perceptibles mediante los sentidos (la forma, el peso, la consistencia, el sabor, el tacto, el olor, la temperatura y la sonoridad); se excluyen: el color, la velocidad y la dimensión, que se tratan por separado.

La mayoría de adjetivos de este grupo suelen dar lugar a pares de antónimos, exceptuando a los de "forma", pues es difícil, en sentido estricto, un opuesto para el término cuadrado o redondo; asimismo no son graduables.

Una cuestión de indudable interés es la que concierne al posible empleo de algunos de estos adjetivos en varios campos sensoriales a la vez: podemos hablar de olor y sabor ácidos, referirnos al sabor y al tacto secos o mencionar un sonido y un sabor dulces. Estos usos no son metafóricos cuando aludimos a un político recto, a una mente cuadrada o a una persona (salada/desabrida/aguda). Hay metáfora si cancelamos un rasgo fundamental del adjetivo en cuestión (...) y trasladamos su uso a la categorización de propiedades morales o evaluativas de seres animados; hay solo flexibilidad interpretativa, en cambio en olor y sabor ácidos. (Demonte, 1999, p.179)

EI LEBAESCO presenta los siguientes adjetivos de propiedad física: forma (redondo, rectangular, cuadrado, triangular, obtuso, recto, punteado, picudo, lacio, colocho, plano, llano), tacto (duro, suave, húmedo, peludo, arenoso, escamoso, pedregoso), peso (liviano, ligero), consistencia (sólido, compacto, tieso, pegajoso, lodoso, resbaloso, cremoso, jugoso y gaseoso), sabor (dulce, agrio, ácido, picante, salado), olor (hediondo), temperatura (caliente, frío, fresco, templado, caluroso) y sonoridad (fuerte, agudo, débil, intenso, sonoro)

Los adjetivos de propiedad física presentes en nuestro inventario léxico son escasos si pretendemos que nuestros niños y jóvenes se expresen de forma fluida y clara; así las cosas, es imperativo que la escuela tome como punto de referencia este modesto inventario y proceda a planificar la incorporación de los términos ausentes, claro está, sin pretender 
ser exahustivo, pues como bien se sabe en cuestiones de léxico es preciso tomar decisiones acertadas, ya que es imposible llevar al aula todo el lexicón de una lengua.

Por otra parte, los adjetivos que describen propiedades físicas son muy útiles para explicitar los primeros pasos del método científico: observación y descripción que, según mi entender, debe trabajar con mayor insistencia la escuela, pues son la base de la investigación científica. En este sentido el alumno debe incorporar a su competencia léxica adjetivos que describan las propiedades de los objetos, por ejemplo deben agregarse a los que ya maneja los siguientes: curvo, convexo, sinuoso, ovalado, al pensar en formas; blando, liso, áspero, rugoso, seco y los que se establecen por analogía, sedoso, aterciopelado, al describir el tacto; pesado, macizo, robusto, espeso, denso, fluido, líquido, al referirse al peso y la consistencia; amargo, picante, soso, desabrido, agridulce, simple, etc., al precisar sabores; podrido, fragante, fétido, ácido, agrio, acre, maloliente, suave, fuerte, dulce, seco aplicados al olor; en fin la lista es interminable, por cuanto la presentada debe tomarse como ejemplos, sin pretenciones de exahustividad.

\subsubsection{Adjetivos de color}

Los adjetivos de color constituyen un conjunto relativamente abierto en el que se incluyen: 1) los términos básicos designadores de color -blanco, negro, gris, etc.-; 2) los adjetivos aproximativos derivados de ellos -rojizo, amarillento, azulado-; los compuestos a que dan lugar -rojiblanco, blanquinegro-; 3) los sustantivos especializados y lexicalizados en significados adjetivos de color, así como los derivados de esos sustantivos -salmón, mostaza, naranja, etc.-; 4) compuestos sintagmáticos formados por un adjetivo de color básico seguido de un sustantivo distinguidor, o de un adjetivo que indica matiz -verde botella, gris perla, amarillo mate, verde oscuro-.

En el LEBAESCO se encuentran los siguientes nombres de colores: blanco, castaño, colorado, gris, verde, morado, anaranjado y macho. Lo reducido de este listado podría obedecer a que los discursos orales emitidos por los informantes no requerían el señalamiento de esta propiedad. Respecto del término macho, para el español de Costa Rica, aplicado al color del cabello, se refiere a pelo rubio o pelo amarillo. 


\subsubsection{Adjetivos de edad}

Los adjetivos de edad constituyen una clase menos amplia que las anteriores y generalmente dan lugar a relaciones de antonimia. Además, los que poseen un significado más general adquieren valor temporal de duración o de relación con el momento del habla.

En el LEBAESCO aparecen los siguientes: nuevo, juvenil, antiguo, moderno, añejo, maduro.

Si bien aparecen adjetivos más especializados como añejo y maduro, están ausentes otros generales, a saber: joven, lejano, anciano, arcaico, reciente, entre otros que deberían trabajarse mediante actividades educativas.

\subsubsection{Adjetivos de valoración o evaluativos}

Parafraseando a Violeta Demonte podemos considerar estos nombres como formas canónicas de los adjetivos calificativos; no obstante, su variación léxico semántica interna es tan diversa, por ejemplo, rico es especialización de bueno para el campo de la comida, de guapo y buen mozo para el campo de la imagen externa, adinerado para el campo económico, etc. Otros como chiva son propios de la jerga de las generaciones más jóvenes en Costa Rica, en este caso con el significado de bonito.

Esta clase de adjetivos es considerada por Dixon como una hiper-clase que cruza a casi todas las anteriores. Además, constituye una manifestación explícita del componente de grado presente en la mayoría de los adjetivos calificativos. Estos adjetivos son graduables y en los casos más generales dan lugar a pares de opuestos; estos términos son antónimos, aunque muchas veces se interpretan como complementarios.

A continuación se citan los adjetivos presentes en el LEBAESCO y en la medida de lo posible, se ordenaran a partir de sus relaciones de polaridad y de sus hipónimos correspondientes.

1. bueno-malo y bonito-feo: bello, lindo, precioso, hermoso, chiva, elegante, lujoso, corrongo, coqueto, sencillo, delicioso, rico, excelente, sobresaliente, sorprendente, perfecto, mejor, agradable, peor, pésimo, terrible, horrible, desagradable.

Al observar la relación de polaridad de estos adjetivos se puede notar que el extremo negativo es menos rico en cantidad de palabras que su opuesto. Igualmente, se nota la 
ausencia de otros calificativos positivos que deberían estar ya incorporados en el vocabulario de expresión del escolar, como por ejemplo: maravilloso, deslumbrante, óptimo y un sin fin más que la escuela debe tratar de incluir en los procesos de planificación de la enseñanza del léxico.

2. rico-pobre, barato-caro, Ileno-vacío-baldío, claro-oscuro, limpio-sucio-cochino, positivo-negativo, homogéneo-heterógeneo, igual-diferente-distinto, fácil-difícilcostoso, silencioso-escandaloso.

Adjetivos pertenecientes a este grupo representan algunos de los antónimos ejemplificados en la escuela, cuando se estudian los calificativos.

3. santo-santificado-sagrado, desnudo-pelado, diverso-variado-vario-común-corriente, famoso-glorioso, brillante-refulgente, ,justo, valioso, fértil, manso, útil, parejo, abundante, importante, interesante, pálido, transparente, postizo, descalzo, chimuelo, orejón, barbudo, manudo.

En este último grupo se ubicaron adjetivos calificativos que no se encuentran en relación de polaridad, pero sí marcan en algunos casos relaciones de gradualidad o sinonimia; también algunos muy coloquiales como chimuelo (desdentado), orejón (que corresponde a un ser animado con orejas grandes o a una persona alcahueta), barbudo (persona con barba abundante), manudo (designa a los seguidores de un equipo de fútbol).

Ahora bien, corresponde a la escuela crear contextos adecuados que coloquen en su justo medio a los adjetivos, en virtud de la situación comunicativa, ya sea formal o informal. Por supuesto, sobre el entendido de que se está trabajando desde un concepto de lengua como diasistema y al objetivo de la promoción de la variedad lingüística prestigiosa, como tarea fundamental de la escuela.

\subsubsection{Adjetivos de aptitudes y (pre)disposiciones humanas}

Este grupo es amplio al igual que el anterior e incluye adjetivos primitivos y derivados que reflejan aptitudes intectuales o emocionales, y pasiones o disposiciones humanas primordiales, desgajadas según variaciones de grado, de perspectiva, o en relación con actividades y actitudes humanas esenciales. 
Estos adjetivos no tienen por lo general antónimos ni complementarios, describen básicamente la posesión de una predisposición o capacidad. Los grados intermedios de la posesión de una determinada aptitud suelen expresarse léxicamente y no por medio de adverbios de medida. No obstante, pueden incluir una gama de términos no estrictamente graduales pero que

sí especifican matices y maneras de ser frente a una predisposición : celoso, desconfiado, receloso, cauto, insensible, indiferente, etc. (...) Todos estos hechos y el tipo de campo nocional implicado, coadyuvan a que esta clase sea la más rica y amplia de todas las clases de adjetivos reseñadas (Op. cit, 181).

Ahora veamos los adjetivos que se refieren a aptitudes y predisposiciones humanas presentes en el LEBAESCO:

1.Aptitudes intelectuales: inteligente, vivo, listo, ágil, mediocre y chapa

La escasez en este grupo podría deberse al hecho de que la escuela costarricense no ha seguido un modelo de comunicación asertivo, en el que la persona expresa sentimientos, emociones y aptitudes propias y de los otros. Es sabida también la dificultad que tienen las personas para describir a los demás y a ellas mismas. Creo que podría estar ahí la debilidad, pues era esperable que aparecieran palabras como despierto, capaz, astuto, hábil, chispa , brillante, y expresiones coloquiales tales como "es un nerdo".

2. Emocionales: amable, gentil, atento, cariñoso, tierno, delicado, estimado, consentido, amigable, amistoso, emocionante, simpático, antipático, serio, creído, desdichado, desgraciado, favorito.

Este grupo presenta la misma característica que el anterior, en el sentido de que es necesario un proceso de comunicación asertivo para que se robustezca y se incorporen palabras como: generoso, cordial, entrañable, odioso, arrogante, entre otras.

3. Pasiones y disposiciones humanas primordiales:

alegre-contento-feliz-triste, agresivo-violento-salvaje-temible-furioso-severocolérico-brusco-bravo-concho-majadero-regañón-mezquino-irrespetuoso, humildesincero-confiable-tranquilo-honrado-respetuoso-honesto-inocente, nervioso-tímido- 
quisquilloso-enfermizo, gracioso-chistoso-picarón-vacilón, confianzudo-repelentedeshonesto-engañoso-perezoso-irresponsable.

\section{Actividades humanas esenciales:}

trabajador, estudioso, protector, dormilón, juguetón, valeroso, vigoroso,

poderoso, valiente, olvidadizo, travieso, tramposo, goloso, mentiroso, obediente, curioso, mujeriego, vegetariano.

En vista de la versatilidad de las personalidades, circunstancias y situaciones propias del ser humano, estos adjetivos tienen la pretensión de servir de punto de partida para la incorporación de otros vocablos de la misma clase.

Un aspecto importante de este tipo de adjetivos es que admiten un prefijo negativo, el cual señala la ausencia de una propiedad que no designa lo contrario de lo expresado por la raíz, en consecuencia, no entran en relaciones de polaridad, por ejemplo:

correcto-incorrecto, cómodo-incómodo, lógico-ilógico, necesario-innecesario, queditoinquieto, impropio, impar, infiel, increíble, invaluable, indebido, intocable, inolvidable, invisible, inválido

El caso de quedito-inquieto, se analizó como quieto-inquieto y no como "quedo-inquieto", pues el positivo de quedito no es quedo, sino que en Costa Rica es usual la forma quieto en vez de quedo. También aparecen ocho adjetivos sin su respectivo par, no obstante, es obvio que los informantes los conocen, aunque no aparecieran en el corpus.

Ahora bien, desde el punto de vista didáctico podría aprovecharse esta particularidad para acopiar junto con los alumnos, adjetivos que admitan el prefijo negativo sin incurrir en agramaticalidades; asimismo, buscar las razones del por qué algunos de estos no permiten variantes con ese tipo de prefijo. Al igual, crear contextos variados para determinar su comportamiento y posible uso. 


\subsection{Adjetivos relacionales}

En vista de las características tan variadas de esta clase de adjetivos es muy difícil realizar algún tipo de análisis que parta únicamente de las entradas léxicas del LEBAESCO. Así las cosas, nos limitaremos a agruparlos según sus características morfológicas. Le corresponderá al maestro, en consecuencia, tomar como guía los contextos y situaciones sintácticas en que aparecen, con el objeto de crear situaciones de aprendizaje en las cuales sea necesario que se aplique el uso de adjetivos relacionales.

Bosque y Picallo, citados por Demonte (1999), consideran que la interpretación última de estos adjetivos ha de realizarse con criterios que tienen que ver con el uso (es decir con criterios pragmáticos), aunque una buena parte de esa interpretación provenga también de un primer análisis léxico-semántico.

A continuación se presentan los ciento setenta adjetivos relacionales que aparecen en el "Léxico básico escolar costarricense: código oral". Debido a la dificultad de organizarlos se optó por considerar sus características morfológicas como criterio de clasificación.

Es claro que desde el punto de vista de la enseñanza, éste no es el mejor camino, por lo que se sugiere al educador que siga un análisis léxico-semántico y pragmático, igualmente se le recomienda que utilice como recurso de apoyo textos periodísticos y administrativos, pues los adjetivos relacionales son mucho más frecuentes en esa prosa que en la narrativa y poética.

-al/-ar (54)

ambiental

fatal

intestinal

oral

artificial

forestal

judicial

ornamental

coloquial

frutal

medicinal

particular

comercial

general

menstrual

parroquial

comunal

grupal

muscular

perjudicial

conceptual

horizontal

musical

personal

dominical

individual

natural

popular

elemental

inferencial

normal

puntual

especial

inicial

nuclear

regional

espinal

integral

occidental

rural

familiar

intertropical

oficial

salival 


\begin{tabular}{|c|c|c|c|}
\hline sexual & triunfal & vial & vulgar \\
\hline termal & tropical & vital & \\
\hline total & vertebral & vocacional & \\
\hline \multicolumn{4}{|l|}{-ico (43) } \\
\hline abiótico & diacrítico & hidráulico & prehistórico \\
\hline acuático & doméstico & hidroeléctrico & prosódico \\
\hline alérgico & económico & hidrográfico & público \\
\hline atómico & eléctrico & histórico & rítmico \\
\hline básico & eólico & honomatopéyic & telefónico \\
\hline bíblico & específico & inmunológico & típico \\
\hline biológico & estratégico & mágico & tónico \\
\hline carbónico & ético & matemático & tóxico \\
\hline cívico & geográfico & numérico & turístico \\
\hline climático & geométrico & ortográfico & volcánico \\
\hline democrático & hemorrágico & pacífico & \\
\hline \multicolumn{4}{|l|}{-ario (11) } \\
\hline binario & literario & primario & solidario \\
\hline circulatorio & ordinario & respiratorio & urinario \\
\hline imaginario & precario & secundario & \\
\hline \multicolumn{4}{|l|}{-ano (6) } \\
\hline átona & humano & profano & \\
\hline cotidiano & mariguano & urbano & \\
\hline \multicolumn{4}{|l|}{-ivo (14) } \\
\hline abusivo & descriptivo & evaluativo & recreativo \\
\hline comprensivo & digestivo & interrogativo & relativo \\
\hline decorativo & educativo & legislativo & \\
\hline deportivo & ejecutivo & narrativo & \\
\hline
\end{tabular}

-il (3)

civil

estudiantial

infantil 
- prefijo

penúltimo, antepenúltimo, extraclase, sobreesdrújula, polisílabo, trisílabo, monosílabo

Otros: (39)

Mercante, naciente, nocturno, nutritivo, privado, ajeno, gratuito,absoluto, íntimo, mixto, potable, feriado, silvestre, licenciado, terrestre, terráqueo, forense, aéreo, carroñero, mayoritario, inerte, comestible, nutritivo, carnívoro, insectívoro, felino, vivíparo, cardiaco, endocrino, , cursiva, manuescrita, unimembre, .

Como puede observarse, en estas listas de adjetivos se percibe claramente la presencia de un léxico que surge gracias al fruto de la interacción permanente en el ambiente educativo. Como ejemplos se entresacan algunos propios de la asignatura de ciencias: intestinal, salival, espinal, forestal, abiótico, atómico, biológico, climático, carbónico, hemorrágico, entre otros; de la asignatura de español: diacrítico, ortográfico, literario, átona, trisílabo, monosílabo, sobreesdrújula, polisílabo, cursiva, manuescrita, unimembre, etc.

Por otra parte, los sufijos más productivos son -al/ar e -ico, dato que podría interesar al estudio de los morfemas en el proceso de adquisición de la lengua materna.

\subsection{Adjetivos adverbiales}

A continuación se presentan los adjetivos adverbiales del corpus; no obstante, debe tenerse en cuenta que todas la formas paralelas a los adjetivos calificativos que, no constituyen expresiones asignadoras de propiedades son adverbiales y, además, estarán representadas por el adverbio correspondiente en -mente (fríamente, largamente/ mirada fría, día largo). Así las cosas, estas listas podrían ampliarme mucho más, pero se ha decidido ubicar aquí únicamente las formas que típicas de estas subclases.

Adjetivos adverbiales intensionales:

Modales: supuesto, posible, mero, escaso y seguro 
Marcadores de intensión o referencia: verdadero, mismo, puro, propio, único, principal, simple, cierto, solo

Adjetivos adverbiales circunstanciales:

Temporales: eterno, permanente, frecuente, usual, diario, próximo, siguiente, previo, anterior, posterios, actual, moderno, antiguo, cercano, lejano, completo, entero, todo, suficiente, mucho, demasiado, tanto, poco.

Locativos: izquierda, derecha, paralelo, junto, céntrico, primero, último.

Manera: estricto, flexible, sereno, directo, etc.

Corresponde al educador crear contextos varios en los que se utilicen este tipo de adjetivos, por ejemplo los adverbiales de manera son muy útiles para especificar la forma en que se realizaron las actividades o eventos y, en consecuencia, contribuyen a la precisión en la descripciones y narraciones.

\section{A manera de conclusión}

En vista de que el adjetivo confiere precisión a los textos y a la vez enriquece la prosa, es imperativo que el sistema educativo costarricense le dedique un espacio mayor en la enseñanza de la lengua, pero teniendo en cuenta que no es solo una categoría gramatical que se estudia como elemento opcional en la oración, al lado del sustantivo, sino que forma parte importante del "enriquecimiento léxico", al igual que el sustantivo, el verbo y el adverbio, para señalar las categorías gramaticales más numerosas en castellano.

Igualmente, es necesario hacer hincapié en que los quinientos veintinueve adjetivos presentes en el LEBAESCO, facilitan la tarea de la planificación de la enseñanza, pues al conocer los adjetivos y sus características, la tarea educativa ya está iniciada y correspondería ahora diseñar las estrategias graduadas de incorporación en cada nivel educativo.

Si bien el léxico básico representa el vocabulario más estable de una lengua, o sea, el que es factible de aparecer independientemente de la situación comunicativa, es necesario 
completarlo con un estudio de disponibilidad, cuyo propósito sea conocer en su totalidad el léxico usado por los educandos costarricenses.

\section{Referencias}

Alarcos Llorach, Emilio. (1994/2000). Gramática de la Lengua Española. Madrid: Espasa Calpe.

Demonte, Violeta. (1999). "El adjetivo: clases y usos. La posición del adjetivo en el sintagma nominal”. Gramática Descriptiva de la Lengua Española. Bosque, Ignacio y Violeta Demonte (editores). Tomo 1. Madrid: Espasa Calpe.

Gómez Torrego, Leonardo. (1997/2000). Gramática didáctica del español. Madrid: Ediciones S.M.

Murillo, Marielos y Víctor Sánchez. (2002). Crecimiento del léxico básico de los escolares costarricenses: código oral. Por aparecer en Revista Káñina.

Murillo, Marielos y Víctor Sánchez. (2002). Léxico básico preescolar costarricense. Editorial de la Universidad de Costa Rica.

Murillo Rojas, Marielos. (2002). Léxico básico escolar costarricense: código oral (LEBAESCO). Sin publicar, en proceso de edición.

Sánchez Corrales, Víctor. (1995). Aportes de la lingüística a la enseñanza del español como lengua materna en Costa Rica: competencia sintáctica de los preescolares. En: Educación. 19 (1): 73-81. 